\title{
EXPERIMENTAL AND MATHEMATICAL ANALYSIS OF A MULTI-LAYER SYSTEM OF RAILWAY TRACK
}

Based on experimental measurement of a model of a multi-layer non-linear system with inserted geosynthetic layers of the permanent way structure, a new design method will be designed for dimensioning the sleeper subgrade structure using classical and geosynthetic materials or sub-ballast vibration-damping matting. The results of measurements on a track structure model in a 1:1 scale performed in a testing box will be verified by means of a numerical model. A two-dimensional solution will be subsequently verified by means of a spatial model. Numerical modelling will serve for transferring the values measured on the experimental model into a current railway track structure.

The Czech Republic has launched a process of gradual modernization of selected, so-called corridor tracks, to allow for train velocities of up to $160 \mathrm{~km} \cdot \mathrm{h}^{-1}$. The railway track construction must be designed in such a way to ensure long-term stability of geometric rail parameters. A necessary precondition for this is a sufficient bearing capacity of the substructure even in climatically unfavourable seasons, ensuring thus the overall needed bearing capacity of the railway track construction. In unfavourable geotechnical conditions, the design practice applies structural layers below the ballast bed using various building materials. Numerous geosynthetic materials are also applied to reinforce individual structural layers. In order to reduce noise and vibrations, elastic subballast matting is used, too. No exact design method for the dimensioning of the track bed bearing construction, however, has been developed to-date, either abroad or in our country. Exploitation of innovative materials in the structural layers of railway tracks is solely based on empirical knowledge obtained from applications implemented at individual sites.

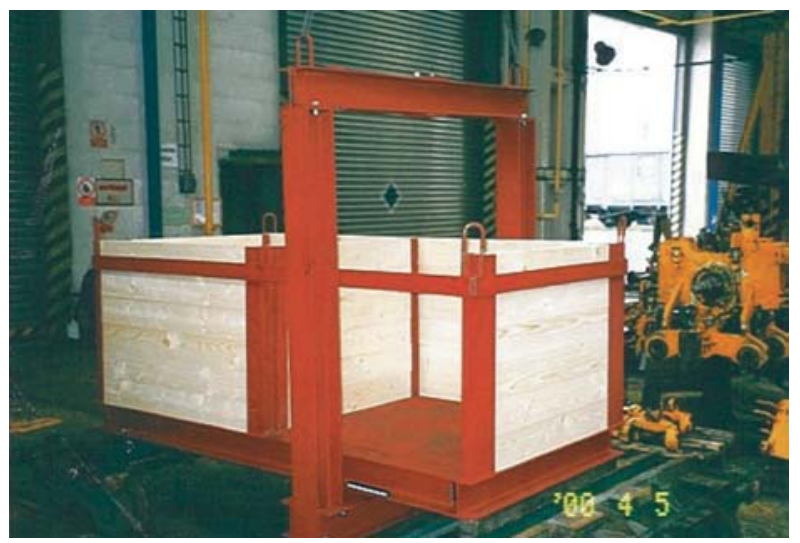

Fig. 1 View of testing box with inserted partition
The project concept is based on a mathematical calculation of the bearing capacity of a multi-layer track bed construction of the railway track, and verification of the results of a theoretical solution by means of experimental measurements carried out on a model of a railway track section in a 1:1 scale in laboratory conditions. Experimental measurements will apply a testing box of the Central laboratories of the Faculty of Civil Engineering, CTU in Prague.

The project output will be an exact design method of the railway track bed bearing construction, which will not only allow designing track bed bearing constructions for various geotechnical conditions, but will also optimize these constructions with regards to cost-effectiveness. The project achievements will be applied in updating selected parts of the ČD S4 Regulation "Substructure", in the operational practice of the Czech Railways as well as in the design practice within the next stage of modernization of railway lines managed by the Czech Railways. Designing optimum railway track constructions with the required load-bearing capacity will be cost-effective, too.

The preconditions for reaching the project objectives are completion of experimental measurements using a track construction model in a 1:1 scale in the testing box (Fig. 1) for:

- a track bed of unbonded layers,

- a track bed of unbonded layers with reinforcing synthetic geotextiles,

- a track bed of unbonded layers with sub-ballast antivibration matting,

the design of numerical models of the railway track construction, verification of the results of experimental measurements by means of a numerical model, verification of the two-dimensional solution of the numerical model of the railway track construction with the help of a three-dimensional model, the development of a new design method of the load-bearing construction of the railway track under

\footnotetext{
* Hana Krejčiříková, Martin Lidmila

Department of Railway Structures, Faculty of Civil Engineering, Czech Technical University, Thákurova 7, 16629 Prague 6, Czech Republic, E-mail: krejcirikova@fsv.cvut.cz
} 
various geotechnical conditions applying different track bed constructions.

The first grant project year (2003) was used for the completion of the following works:

Verification of the behaviour of the railway superstructure and substructure subjected to loading in the testing box was a basis for the design of measurement methodology.

Measurement methodology was designed and verified using a model of the railway superstructure and substructure construction. The following track bed construction was selected for verification:

- ballast bed 32-63 mm with a thickness of $35 \mathrm{~cm}$,

- a layer of partially crushed gravel 0-32 $\mathrm{mm}$ with a thickness of $15 \mathrm{~cm}$,

- rubber plates with a thickness of $54 \mathrm{~mm}$ simulating subgrade with a bearing capacity of $15 \mathrm{MPa}$.

The track bed was loaded with a half of a concrete sleeper B $91 \mathrm{~S}$ with a piece of a rail UIC 60 , which was exposed to a force of $50 \mathrm{kN}$. The loaded model was used for the measurement of the following parameters:

a)

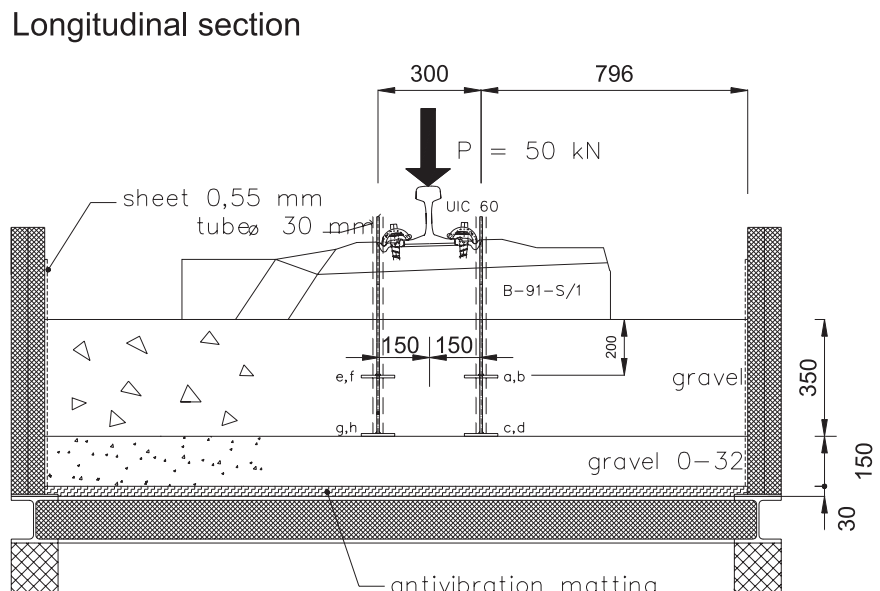

- sleeper subsidence,

- ballast bed subsidence,

- simulated subgrade subsidence (Fig. 2),

- moduli of deformability on the ballast bed surface, on the surface of the layer of partially crushed gravel and on the surface of rubber plates (Fig. 3),

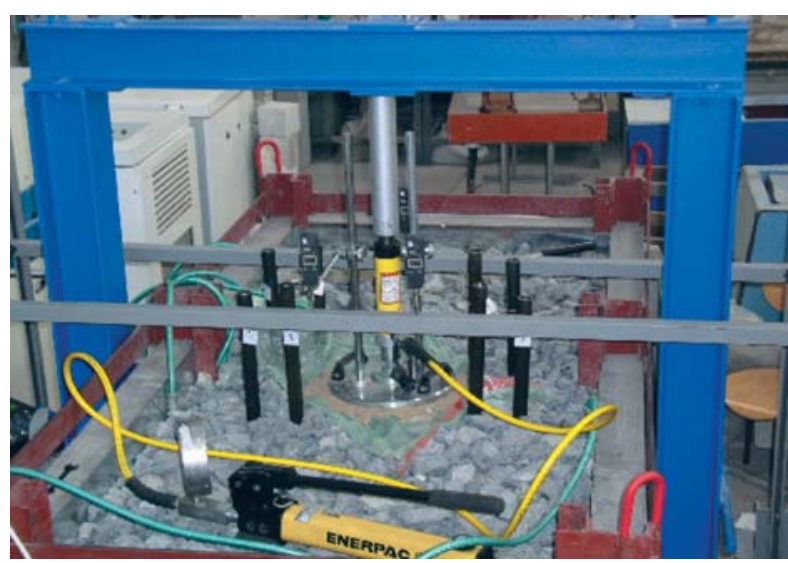

Fig. 3 View of a measurement of modulus of deformability on the ballast bed surface in testing box

\section{Cross section}

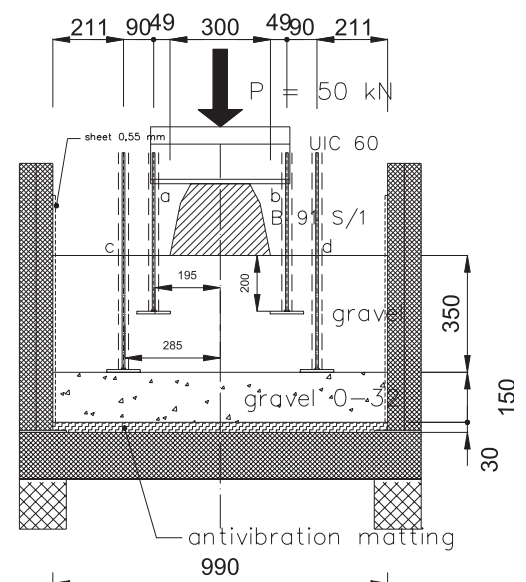

b)

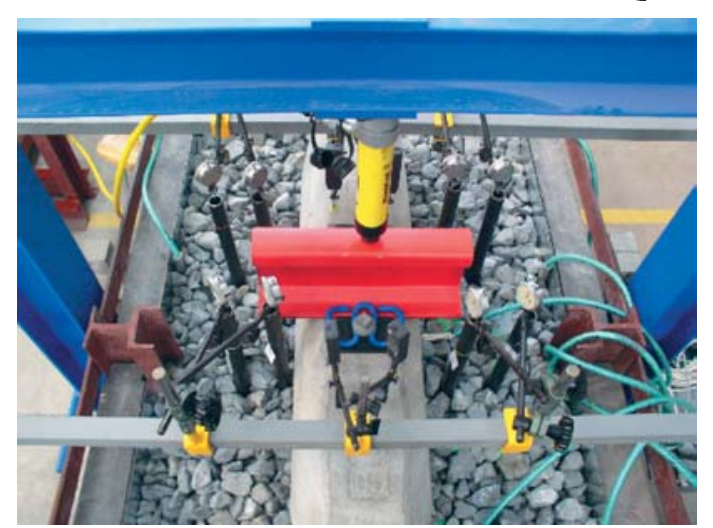

Fig. 2 Measurement of sleeper subsidence under load of rail by hydraulic set ENERPAC with a force of $0-50 \mathrm{kN}$ a) scheme b) view 

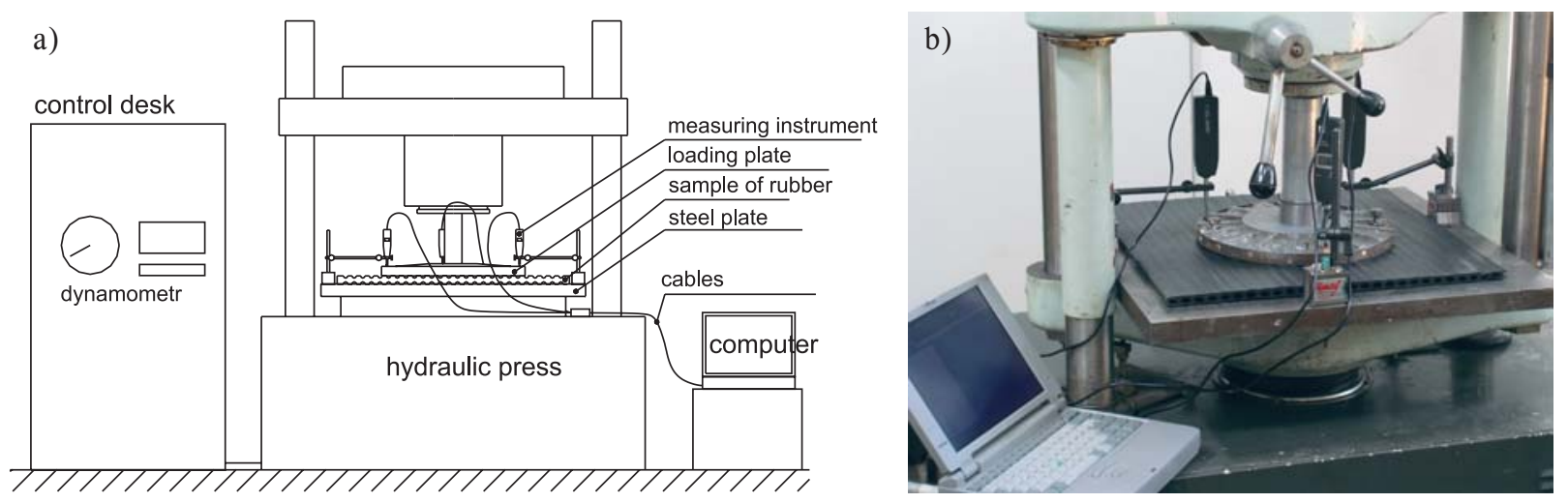

Fig. 4 Measurement of static modulus of deformability of sub-ballast matting VM 12-01,

a) scheme of measurement unit fabric, b) view of measurement unit

- stress at the level of sleeper loading area, on the surface of the layer of partially crushed gravel and on the surface of rubber plates simulating the subgrade.

The measurements of moduli of deformability on sub-ballast antivibration matting of Phoenix VM 12-01 brand laid on a stiff base were made.

Experimental investigation of the effect of sub-ballast antivibration matting of Phoenix VM 12-01 brand on the overall bearing capacity of the track bed was performed (Fig. 4).

This investigation applied the following track bed model in the testing box:

- ballast bed 32-63 mm with a thickness of $35 \mathrm{~cm}$,

- with and without a layer of partially crushed gravel with a thickness of $15 \mathrm{~cm}$,

- sub-ballast antivibration matting of Phoenix VM 12-01 brand,

- stiff base (testing box bottom) or simulated subgrade consisting of a layer of partially crushed gravel with a thickness of $12 \mathrm{~cm}$ laid on a layer of rubber with a thickness of $30 \mathrm{~mm}$, which was laid on a stiff base (testing box bottom).

A measurement of modulus was performed in three unoverlaping places situated by longitudinal axe of the testing box. Results of measurement are given on Fig. 5.

(Numeral values determined modulus of deformability on the construction in the level of labelled layer.)

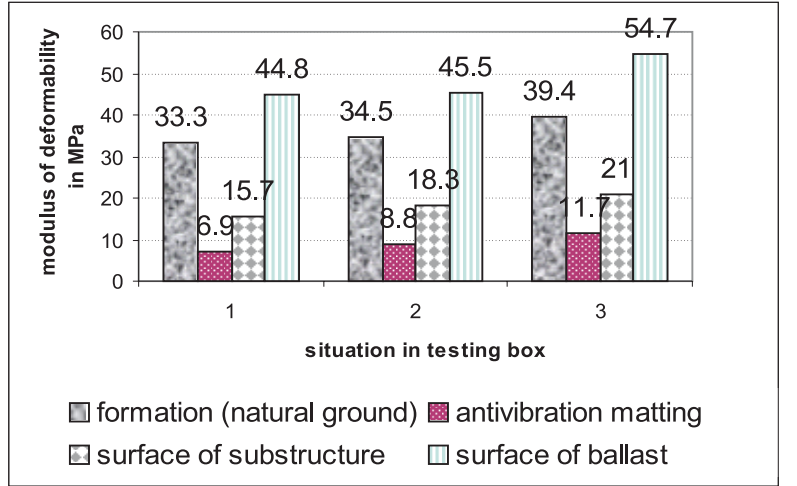

Fig. 5 Results of measurement of static modulus of deformability in testing box

The project results and their exploitation in the operational practice of the Czech Railways will contribute to a more objective design of the load-bearing construction of the railway track. At the same time, they will facilitate the design of a construction with optimum cost-effectiveness. The analysis of the railway track construction also represents a general solution of the distribution of force effects due to railway operation within the construction of a multi-layer track bed system. The project is aimed at developing an innovative design method for dimensioning the track bed construction using standard building materials as well as geosynthetics, or using sub-ballast antivibration matting.

\section{References:}

[1] KREJČIŘÍKOVÁ, H., TYC, P.: Geomembranes for ČD Tracks, conference „Geosynthetics in Transport Construction”, 2003,

[1] KREJČIŘÍKOVÁ, H.: Railway Track Stiffness as one of its Characteristics, II. Miedzynarodowa konferencja Naukowo-Techniczna, Wroclaw, 2003, pp. 29-32,

[1] HORNÍČEK, LIDMILA, M.: The Effect of Antivibration Matting on the Tram Track Bearing Capacity, the professional conference of doctoral students, volume 10 - Construction Management Economics, VUT Brno, Faculty of Civil Engineering, 2003, pp. 97-101. 